\title{
Effects of paclitaxel intervention on pulmonary vascular remodeling in rats with pulmonary hypertension
}

\author{
JIAN ZHAO ${ }^{1}$, MEIFANG YANG ${ }^{2}$, XINDAN WU $^{3}$, ZHANGYA YANG $^{4}$, PENG JIA ${ }^{1}$,

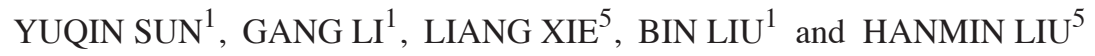 \\ ${ }^{1}$ Department of Pediatric Cardiology, The Affiliated Hospital of Southwest Medical University; \\ ${ }^{2}$ School of Nursing, Southwest Medical University, Luzhou, Sichuan $646000 ;{ }^{3}$ Department of Pediatrics, \\ Chengdu Women and Children's Central Hospital, Chengdu, Sichuan 610091; ${ }^{4}$ Department of Pediatrics, \\ Xinqiao Hospital, Third Military Medical University, Chongqing 400037; ${ }^{5}$ Department of Pediatric Cardiology, \\ West China Second University Hospital, Chengdu, Sichuan 610041, P.R. China
}

Received October 23, 2016; Accepted March 23, 2018

DOI: $10.3892 /$ etm.2018.7045

\begin{abstract}
The aim of the present study was to investigate the effects of paclitaxel (PTX), at a non-cytotoxic concentration, on pulmonary vascular remodeling (PVR) in rats with pulmonary hypertension $(\mathrm{PAH})$, and to explore the mechanisms underlying the PTX-mediated reversal of PVR in PAH. A total of 36 rats were divided into control group $(n=12)$, model group $(\mathrm{n}=12)$ receiving a subcutaneous injection of monocrotaline $(60 \mathrm{mg} / \mathrm{kg})$ in the back on day 7 following left pneumonectomy and PTX group $(\mathrm{n}=12)$ with PTX $(2 \mathrm{mg} / \mathrm{kg})$ injection via the caudal vein 3 weeks following establishing the model. The degree of PVR among all groups, as well as the expression levels of Ki67, p27 ${ }^{\mathrm{Kipl}}$ and cyclin B1, were compared. The mean pulmonary artery pressure, right ventricular hypertrophy index [right ventricle/(left ventricle + septum) ratio] and the thickness of the pulmonary arterial tunica media in the model group were $58.34 \pm 2.01 \mathrm{mmHg}, 0.64 \pm 0.046$ and $65.3 \pm 3.3 \%$, respectively, which were significantly higher when compared with $23.30 \pm 1.14 \mathrm{mmHg}, 0.32 \pm 0.028$ and $16.2 \pm 1.3 \%$ in the control group, respectively $(\mathrm{P}<0.01)$. The mean pulmonary artery pressure, right ventricular hypertrophy index and thickness of the pulmonary arterial tunica media in the PTX group were $42.35 \pm 1.53 \mathrm{mmHg}, 0.44 \pm 0.029$ and $40.5 \pm 2.6 \%$, respectively, which were significantly lower when compared
\end{abstract}

Correspondence to: $\mathrm{Dr}$ Bin Liu, Department of Pediatric Cardiology, The Affiliated Hospital of Southwest Medical University, 25 Taiping Street, Luzhou, Sichuan 646000, P.R. China

E-mail: binliudoc@126.com

Dr Hanmin Liu, Department of Pediatric Cardiology, West China Second University Hospital, 17 People South Road, Chengdu, Sichuan 610041, P.R. China

E-mail: hanminlu@sina.com

Key words: pulmonary hypertension, pulmonary vascular remodeling, cell cycle, paclitaxel with the model group $(\mathrm{P}<0.01)$. Compared with the control group, the expression levels of Ki67 and cyclin B1 in the model group were significantly increased $(\mathrm{P}<0.01)$, while p27 $7^{\mathrm{Kip} 1}$ expression was significantly reduced $(\mathrm{P}<0.01)$. Following PTX intervention, the expression levels of Ki67 and cyclin B1 were significantly reduced when compared with the model group $(\mathrm{P}<0.01)$, while $\mathrm{p} 27^{\mathrm{Kipl}}$ expression was significantly increased $(\mathrm{P}<0.01)$. The results of the present study suggest that PTX, administered at a non-cytotoxic concentration, may reduce $\mathrm{PAH}$ in rats, and prevent the effects of PVR in PAH. These effects of PTX may be associated with increased expression of $\mathrm{p} 27^{\mathrm{Kip} 1}$ and decreased expression of cyclin B1.

\section{Introduction}

Prevalence of pulmonary hypertension (PAH) was reported as $0.3-6 \%$ in 2014, with the left heart disease being the most prominent, followed by pulmonary disease and chronic thromboembolic pulmonary hypertension (1). The proportion of all PAH-associated emergency department visits has decreased and so have mortality rates (2). The abnormal proliferation of vascular smooth muscle cells (VSMCs) is a key pathological feature of pulmonary vascular remodeling (PVR) and occlusion in PAH (3). As our understanding of PAH increases, the drug treatments available have improved considerably. Vasodilator agents are the standard method of drug treatment; however, recent strategies have focused on developing anti-proliferative agents $(4,5)$, which have already made some progress.

In recent years, certain antineoplastic agents have exhibited robust inhibitory effects on angiogenesis, when administered at low non-cytotoxic concentrations (4). These anticancer drugs have provided novel ideas for identifying effective treatment methods against vascular proliferative diseases. A previous study demonstrated that, at nanoscale concentrations, the anti-cancer drug paclitaxel (PTX) exhibited significant inhibitory effects on the proliferation of VSMCs (6), thus ultimately achieving the purpose of anti-proliferation. As an anti-proliferative drug, PTX has been used in the clinical prevention and treatment of coronary restenosis following coronary heart disease or additional cardiovascular diseases (7). 
PTX exhibited satisfactory results in preventing drug-eluting stent-induced restenosis, as well as its use as a drug-eluting stent (8-10). The U.S. Food and Drug Administration have approved a PTX-eluting stent for marketing (11). Therefore, the clinical applications of PTX have already been extended to vascular proliferative diseases (12); however, a limited number of studies conducted thus far have focused on the application of PTX in PAH, and the mechanism of anti-PVR in PAH remains unclear.

PTX inhibits cell proliferation using a unique biological mechanism. It effectively inhibits the $\mathrm{G}_{2} / \mathrm{M}$ cell cycle phase, thus leading to inhibition of cell proliferation (13). Cyclin B1 is a key regulatory protein at the $\mathrm{G}_{2} / \mathrm{M}$ checkpoint (14). In recent decades, the cyclin-dependent protein kinase inhibitor, $\mathrm{p} 27^{\mathrm{Kip} 1}$, has gained increasing attention. Although the majority of research regarding $\mathrm{p} 27^{\mathrm{Kipl}}$ has focused on its control of cell proliferation and expression in tumor cells (15), its negative regulation of the proliferation of VSMCs has gained increasing attention (16-18).

In the current study, a rat model of PAH was generated, and rats were administered with PTX at a dose of $2 \mathrm{mg} / \mathrm{kg}$, according to the literature (19). This dose was thought to increase the plasma concentration of PTX at the nanoscale level in vivo, and is markedly lower than that required for cancer treatment. The results of a previous study suggest that this concentration may inhibit the proliferation of VSMCs without affecting the activity of normal cells (6). The PAH model generated in the present study, was established to investigate the effects and mechanism of PTX on PVR in PAH. The results provide experimental evidence for a novel approach to the prevention and reversal of PVR in PAH.

\section{Materials and methods}

Animals and grouping. A total of 36 male specific-pathogen free Sprague-Dawley rats (age, 6-8 weeks; weight, 300-350 g) were provided by animal lab of the West China Animal Center of Sichuan University (Chengdu, China). Rats were kept in a conventional room at $22 \pm 2^{\circ} \mathrm{C}$, a relative humidity of $55 \pm 10 \%$ and a 12-h light/dark cycle. Rats had access to food and water ad libitum. The rats were divided into the following three equal groups at random: Control group, where rats received no treatment; model group, where rats underwent a left pneumonectomy plus subcutaneous injection of $60 \mathrm{mg} / \mathrm{kg}$ monocrotaline (MCT; Sigma-Aldrich; Merck KGaA, Darmstadt, Germany), a natural ligand exhibiting dose-dependent cytotoxicity with potent antineoplastic activity (20), at 7 days following the procedure; PTX group, where rats underwent the same procedure as those in the model group plus administration of $2 \mathrm{mg} / \mathrm{kg}$ PTX (Chongqing Pharmaceutical Group Co., Ltd., Yuzhong, China) via the caudal vein (21) daily for 1 week at 3 weeks following injection of MCT (6). Tests were performed and samples were collected from rats in all groups at 1 week following treatment. Following intramuscular injection of atropine $(22.5 \mu \mathrm{g} / \mathrm{kg})$ and intraperitoneal injection of chloral hydrate $(10 \%, 400 \mathrm{mg} / \mathrm{kg})$ for anesthesia, the diastolic pressure and waveform of right atrium were recorded. Left lungs were placed in $1.5 \mathrm{ml}$ tube and frozen in liquid nitrogen. Following the measurement, right lung specimens were dissected, perfused and fixed with $4 \%$ paraformaldehyde for $48 \mathrm{~h}$ at room temperature. Right lung segments were placed in PBS and $7 \times 7 \mathrm{~mm}^{2}$ pieces were prepared. The present study was performed in strict accordance with the recommendations in the Guide for the Care and Use of Laboratory Animals of the National Institutes of Health. The animal use protocol was reviewed and approved by the Experiment Animal Administrative Committee of Sichuan University (Chengdu, China).

Detection of hemodynamic parameters and tissue preparation. The mean pulmonary artery pressure (mPAP) and the right ventricular hypertrophy index [ratio of right ventricle $(\mathrm{RV})$ to left ventricle + septum $(\mathrm{LV}+\mathrm{S})]$ were detected as previously described (22). Right lung tissues $\left(7 \times 7 \mathrm{~mm}^{2}\right)$ were subjected to hematoxylin $(0.5 \% ; 5-10 \mathrm{~min})$ and eosin $(1.0 \% ; 3-5 \mathrm{~min})$ staining at room temperature, immunohistochemistry and elastic Van Gieson staining (0.22\% Verhoeff solution; room temperature; 15-60 $\mathrm{min}$ ), and the percentage wall thickness (WT) was measured as previously described (23). In addition, the neointimal proliferation degree of the pulmonary artery was determined as described previously (24). WT was defined as the distance between the internal and external elastic plates. The elastic plate diameter (ED) was defined as the average diameter of the outer elastic plate. For quantification of elastic Van Gieson staining of tissue slices, the following formula was used: WT $(\%)=(2 \times W T / E D) \times 100 \%$. The degree of neointimal proliferation was calculated as follows: Neointimal proliferation $(\%)=($ number of neointimal vessels $/ 50) \times 100$.

Immunohistochemistry. Left lung samples (4 $\mu \mathrm{m})$ were washed in water for $15 \mathrm{~min}$ following dewaxing (xylene for $5 \mathrm{~min}$; xylene and ethanol (1:5) for $5 \mathrm{~min}$; xylene and ethanol (1:1) for $5 \mathrm{~min}$ ) and incubated with $3 \% \mathrm{H}_{2} \mathrm{O}_{2}$ for $10 \mathrm{~min}$ all at room temperature. Following the antigen was repaired at $95^{\circ} \mathrm{C}$ for $20 \mathrm{~min}$ and the slices were blocked by $0.1 \%$ goat serum (Beijing Solarbio Science \& Technology Co., Ltd., Beijing, China) at room temperature for $15 \mathrm{~min}$. Sections were subsequently incubated with primary antibodies against Ki67 (ab15580, 1:100), p27 $7^{\mathrm{Kip} 1}$ (ab7961, 1:100) and cyclin B1 (ab2949, 1:100; all provided by Abcam, Cambridge, MA, USA) at $4^{\circ} \mathrm{C}$ overnight, followed by incubation with second antibody $(1 \%$ biotin-labeled goat anti-mouse IgG; ab47844; Abcam) at $37^{\circ} \mathrm{C}$ for $15 \mathrm{~min}$. This was followed by incubation with horseradish peroxidase-labeled streptomyces ovalbumin at $37^{\circ} \mathrm{C}$ for $15 \mathrm{~min}$ and staining with diaminobenzidine (DAB) for 10-30 min at room temperature. The immunohistochemical results were analyzed using Image-Pro Plus software 6.0 (Media Cybernetics, Inc., Rockville, MD, USA) and semi-quantified to obtain integrated optical density (IOD) values. For each animal, 20 random visual fields of view were observed using an optical microscope (magnification, x400) and an average IOD value calculated.

Western blot analysis. Total protein was extracted from $100 \mathrm{mg}$ lung tissue following lysis using TRIzol (Thermo Fisher Scientific, Inc., Waltham, MA, USA). The total protein concentration was determined using a bicinchoninic acid assay. A total of $100 \mu \mathrm{g}$ total protein was subjected to $10 \%$ SDS-PAGE, and then transferred onto a polyvinylidene difluoride membrane. Membranes were incubated with rabbit anti-rat p27 $7^{\mathrm{Kip} 1}$ (ab7961; 1:2,000; Abcam) and mouse anti-rat cyclin B1 
Table I. Comparison of mPAP, RV/(LV+S) ratio, WT and degree of neointimal proliferation.

\begin{tabular}{lrlllr}
\hline Group & $\mathrm{n}$ & $\mathrm{mPAP}, \mathrm{mmHg}$ & $\mathrm{RV} /(\mathrm{LV}+\mathrm{S})$ & $\mathrm{WT}, \%$ & Neointimal proliferation, \% \\
\hline Control & 12 & $23.30 \pm 1.14$ & $0.32 \pm 0.03$ & $16.2 \pm 1.3$ & 0 \\
Model & 7 & $58.34 \pm 2.01^{\mathrm{a}}$ & $0.64 \pm 0.05^{\mathrm{a}}$ & $65.3 \pm 3.3^{\mathrm{a}}$ & $85.64 \pm 6.23$ \\
Paclitaxel & 10 & $42.35 \pm 1.53^{\mathrm{a}, \mathrm{b}}$ & $0.44 \pm 0.03^{\mathrm{a}, \mathrm{b}}$ & $40.5 \pm 2.6^{\mathrm{a}, \mathrm{b}}$ & $58.45 \pm 7.84^{\mathrm{b}}$
\end{tabular}

${ }^{\mathrm{a}} \mathrm{P}<0.01$ vs. control group; ${ }^{\mathrm{b}} \mathrm{P}<0.01 \mathrm{vs}$. model group. mPAP, mean pulmonary artery pressure; $\mathrm{RV}$, right ventricle; $\mathrm{LV}$, left ventricle; $\mathrm{S}$, septum; WT, wall thickness.
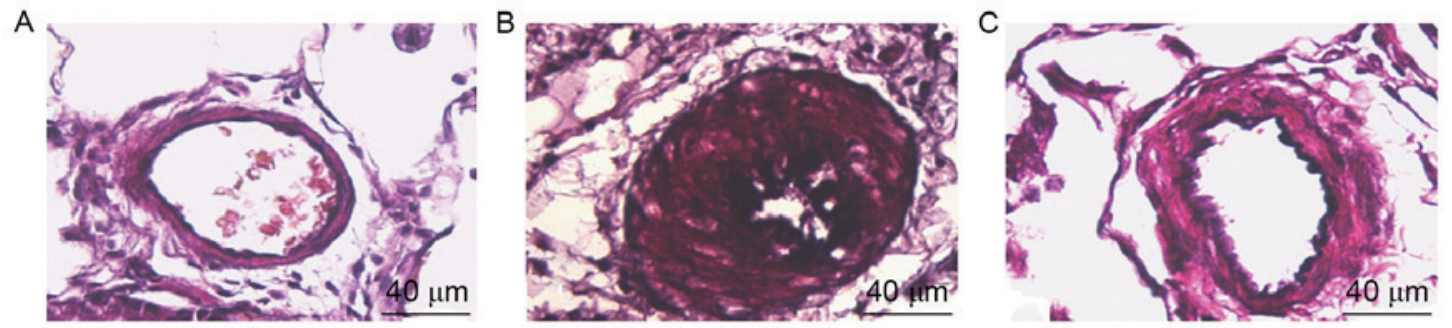

Figure 1. Elastic Van Gieson staining of lung vessels in rats from each experimental group (magnification, x400). (A) Control group. (B) Model group. (C) Paclitaxel group.

(ab2949; 1:1,000; Abcam) in 0.05\% Tris-buffered saline and Tween 20 (TTBS) and $1 \%$ nonfat dry milk at $4^{\circ} \mathrm{C}$ overnight. The internal control was GAPDH mouse monoclonal antibody (AF0006; 1:1,000; Beyotime Institute of Biotechnology, Haimen, China). The membrane was then thoroughly washed with TTBS and subsequently incubated with the horseradish peroxidase-conjugated goat anti-rabbit IgG (ab6795; 1:3,000; Abcam) and goat anti-mouse (ab102454; 1:1,000; Abcam) secondary antibody (ab47844; 1:3,000; Abcam) at room temperature for $1 \mathrm{~h}$. This was followed by incubation with $5 \%$ nonfat dry milk-containing TTBS buffer at room temperature for $1 \mathrm{~h}$. The protein-antibody complex was detected by enhanced chemiluminescence (BeyoECL Star; Beyotime Institute of Biotechnology). The protein bands were visualized and their expression intensities were measured using Intas Gel IX 2.0 (Bio Olympics Ltd; Beverly Hills, CA, USA). p27 ${ }^{\text {Kip1 }}$ and cyclin B1 expression were normalized to GAPDH. The experiment was performed in triplicate.

Statistical analysis. Experimental results are expressed as the mean \pm standard deviation. Statistical analysis was performed using one-way analysis of variance. For group comparisons, the least significant difference post hoc test was employed. The SPSS software program (version, 16.0; SPSS, Inc., Chicago, IL, USA) was used for statistical analysis. $\mathrm{P}<0.05$ was considered to indicate a statistically significant difference.

\section{Results}

Comparison of hemodynamic parameters. At day 35 following the left pneumonectomy procedure, 5 rats in the model group and 2 rats in the PTX group died, due to PAH symptoms on days 17 in the model group and on days 26 and 29 in the PTX group. The mPAP in the model group was significantly higher compared with the control group $(\mathrm{P}<0.01)$, whereas mPAP in the PTX group was significantly decreased when compared with the model group $(\mathrm{P}<0.01$; Table I). These results suggest that PTX may significantly reduce mPAP in rats with PAH.

Comparison of $R V /(L V+S)$ ratio and $W T$. The $\mathrm{RV} /(\mathrm{LV}+\mathrm{S})$ ratio and WT in the model group was $0.64 \pm 0.046$ and $65.3 \pm 3.3 \%$, respectively, which was significantly higher when compared with $0.32 \pm 0.028$ and $16.2 \pm 1.3 \%$ in the control group, respectively $(\mathrm{P}<0.01$; Table I). The $\mathrm{RV} /(\mathrm{LV}+\mathrm{S})$ and $\mathrm{WT}$ in the PTX group was $0.44 \pm 0.029$ and $40.5 \pm 2.6 \%$, respectively, which was significantly lower when compared with the model group $(\mathrm{P}<0.01$; Table I). This suggested that PTX significantly alleviated right ventricular thickening and pulmonary arterial tunica media thickening induced by pneumonectomy and MCT.

Comparison of neointimal proliferation degrees. Elastic Van Gieson staining was performed to observe the rate of neointimal proliferation in rats from each experimental group. The staining revealed the blood vessel wall, lumen, internal and external elastic plates (with lace-like structures), and the neointima inside the internal elastic plate of small lung blood vessels. The results indicated that no neointimal formation had occurred in rats from the control group, whereas rats in the model group exhibited a marked increase in neointimal formation, with the small vascular lumen almost completely obstructed in severe cases (Table I; Fig. 1). PTX intervention significantly reduced the rate of neointimal proliferation when compared with the model group $(\mathrm{P}<0.01$; Table I; Fig. 1).

Comparison of lung VSMC proliferation. Ki67 expression was primarily distributed in the pulmonary artery wall, peripheral vascular wall and tracheal epithelial cells, as indicated by brown positively-stained cells in immunohistochemical tissue sections (magnification, x200; Fig. 2), which were used to determine the extent of lung VSMC proliferation. The 
Table II. Expression of Ki67, p27 $7^{\mathrm{Kip} 1}$ and cyclin B1 in lung vascular smooth muscle cells.

\begin{tabular}{lrcrc}
\hline & \multicolumn{4}{c}{ Relative expression (integrated optical density) } \\
\cline { 2 - 5 } Group & $\mathrm{n}$ & Ki67 & $\mathrm{p} 27^{\mathrm{Kip} 1}$ & Cyclin B1 \\
\hline Control & 12 & $23.5 \pm 2.1$ & $1,417.5 \pm 255.5$ & $423.5 \pm 81.7$ \\
Model & 7 & $426.7 \pm 70.4^{\mathrm{a}}$ & $256.4 \pm 62.6^{\mathrm{a}}$ & $1,796.2 \pm 206.8^{\mathrm{a}}$ \\
Paclitaxel & 10 & $178.6 \pm 26.0^{\mathrm{a}, \mathrm{b}}$ & $922.3 \pm 234.2^{\mathrm{a}, \mathrm{b}}$ & $905.8 \pm 154.7^{\mathrm{a}, \mathrm{b}}$ \\
\hline
\end{tabular}

${ }^{\mathrm{a}} \mathrm{P}<0.01$ vs. control group; ${ }^{\mathrm{b}} \mathrm{P}<0.01$ vs. model group.
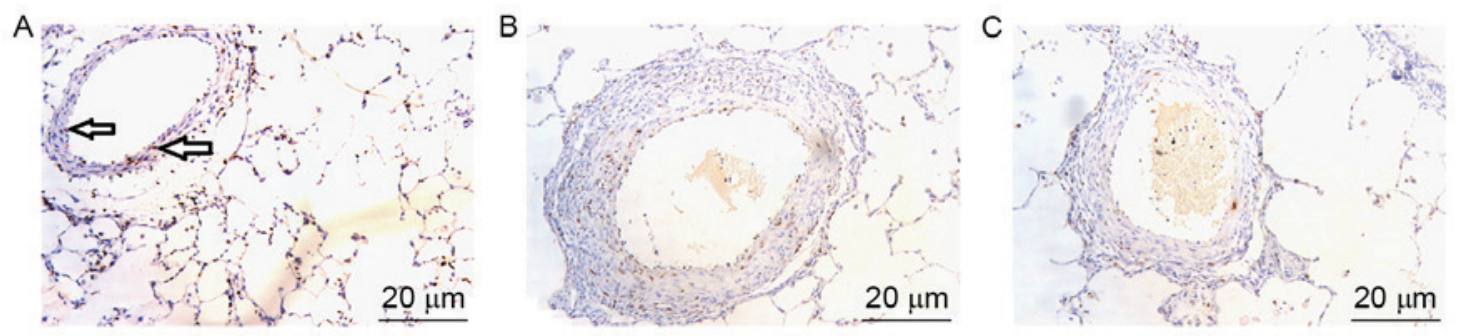

Figure 2. Comparison of Ki67 expression in lung vascular smooth muscle cells from each group (magnification, x200). (A) Control group, with arrows indicating Ki67 expressing cells. (B) Model group. (C) Paclitaxel group.

semi-quantitative analysis of Ki67 expression was achieved by calculating the IOD values, which indicated that Ki67 expression in the model group, was significantly increased when compared with the control group $(\mathrm{P}<0.01$; Table II; Fig. 2). By contrast, Ki67 expression in the PTX group was decreased significantly when compared with the model group $(\mathrm{P}<0.01$; Table II; Fig. 2). The results suggest that PTX may inhibit the proliferation of lung VSMCs in rats with $\mathrm{PAH}$.

Immunohistochemical analysis. p27 $7^{\mathrm{Kip} 1}$ - and cyclin B1-positive cells were characterized by brown or tan particles in the nuclei and cytoplasm of lung VSMCs (Fig. 3). The semi-quantitative analysis of $\mathrm{p} 27^{\mathrm{Kip} 1}$ and cyclin $\mathrm{B} 1$ expression was achieved by determining the IOD values. The results revealed that the expression of $\mathrm{p} 27^{\mathrm{Kip} 1}$ protein in the model group was significantly reduced when compared with the control group $(\mathrm{P}<0.01)$, whereas $\mathrm{p} 27^{\mathrm{Kip} 1}$ expression in the PTX group was significantly decreased when compared with the model group $(\mathrm{P}<0.01$; Table II; Fig. 3). The expression of cyclin B1 protein in the model group was significantly increased compared with the control group ( $\mathrm{P}<0.01$; Table II; Fig. 3). By contrast, cyclin B1 expression in the PTX group was significantly reduced when compared with the model group ( $\mathrm{P}<0.01$; Table II; Fig. 3).

Western blot analysis. Western blot analysis was performed to determine the protein expression levels of $\mathrm{p} 27^{\mathrm{Kip} 1}$ and cyclin B1, with GAPDH as the internal control. Compared with the control group, the expression of $\mathrm{p} 27^{\mathrm{Kip} 1}$ protein in the model group was significantly lower when compared with the control group $(\mathrm{P}<0.01)$, whereas its expression in the PTX group was significantly increased when compared with the model group $(\mathrm{P}<0.01$; Fig. 4). The expression of cyclin $\mathrm{B} 1$ protein in the model group was significantly increased compared with the control group ( $\mathrm{P}<0.01$; Fig. 4). By contrast, cyclin $\mathrm{B} 1$ expression was significantly decreased in the PTX group when compared with the model group ( $\mathrm{P}<0.01$; Fig. 4).

\section{Discussion}

PAH is a disease primarily characterized by PVR (25). Pathological studies have indicated that VSMCs serve a key role in the development of $\mathrm{PAH}$, and may therefore present a therapeutic target for PAH in the future. PTX is a commonly used anticancer drug with applications as chemotherapy drug in in breast cancer, ovarian cancer, head and neck cancer, esophageal cancer, lung cancer and others (26), applications in skin disorders, renal and hepatic fibrosis, inflammation, axon regeneration, limb salvage, and coronary artery restenosis (27). The effective therapeutic concentration of PTX ranges from $1 \mathrm{nmol} / 1$ to $100 \mu \mathrm{mol} / \mathrm{l}$. The highest concentration primarily exhibits cytotoxic effects, whereas lower concentrations (1-200 nmol/l) primarily inhibit the proliferation of cells, thereby inhibiting cell proliferation, migration, intercellular transportation and transmembrane signal transduction, as well as inhibiting subsequent neointimal proliferation $(28,29)$. Previous studies have demonstrated that PTX inhibits the proliferation of VSMCs in a dose-dependent manner in vitro and in vivo (30-33). In addition, PTX has been observed to inhibit angiogenesis in a notable dose-dependent manner within the 3.5-14 nmol/1 concentration range in a chick embryo chorioallantoic membrane model $(34,35)$. The current study applied PTX to a rat model of PAH, and investigated the effects of PTX on PVR and the proliferation of VSMCs.

In the present study, a left pneumonectomy was performed with MCT treatment to establish a rat model of PAH, which was characterized by a significant increase in mPAP, hypertrophy of the RV and pulmonary arterial tunica media and severe neointimal formation and luminal occlusion. Following 

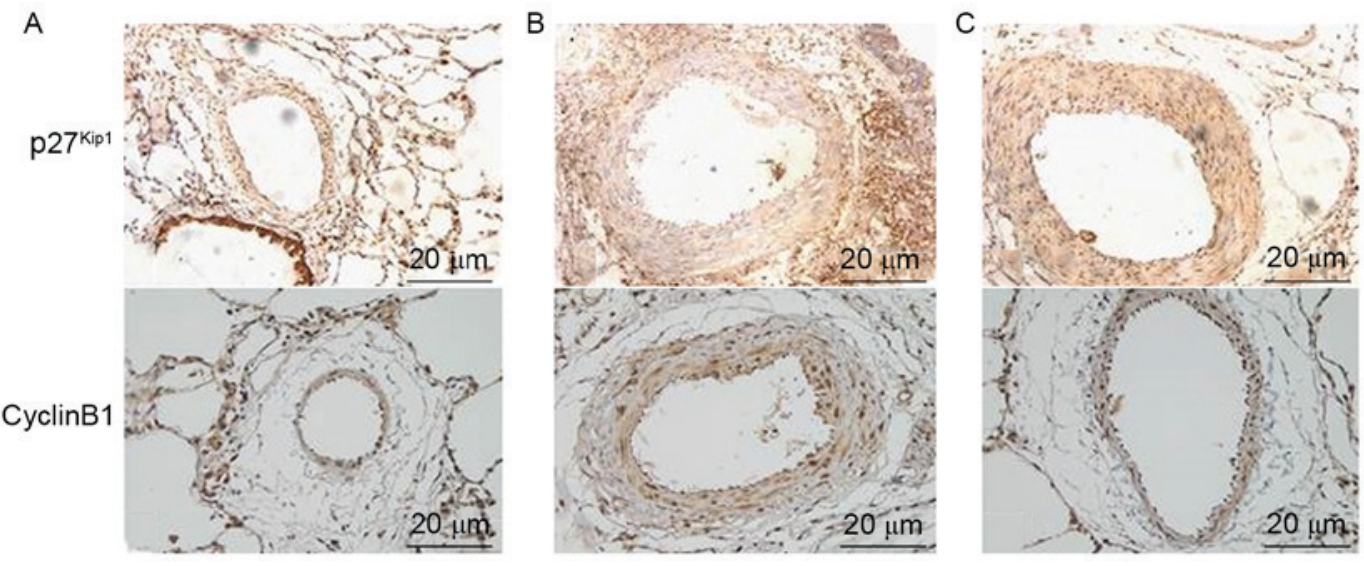

Figure 3. Comparison of $\mathrm{p}^{\mathrm{Kip1}}$ and cyclin B1 expression in lung vascular smooth muscle cells from rats in each experimental group (magnification, $\mathrm{x} 200$ ). (A) Control group. (B) Model group. (C) Paclitaxel group.

A

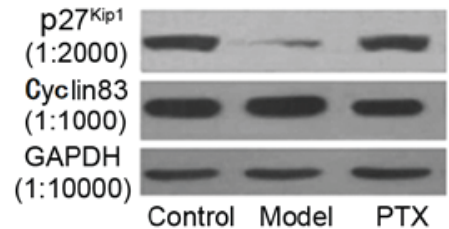

B

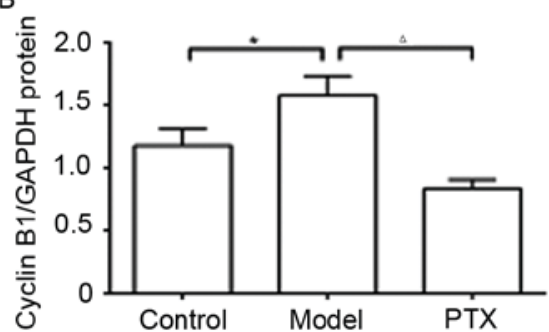

C

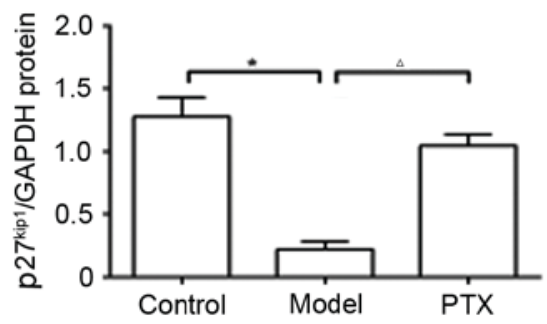

Figure 4. Expression of p27 $7^{\mathrm{Kip} 1}$ and cyclin B1 in lung tissues from rats in the control, model and PTX groups. (A) Western blot analysis of protein expression. Densitometric analysis of (B) cyclin B1 and (C) p27 ${ }^{\mathrm{Kip} 1}$ expression. ${ }^{*} \mathrm{P}<0.01$ vs. control group; ${ }^{\Delta} \mathrm{P}<0.01 \mathrm{vs}$. model group. PTX, paclitaxel.

PTX intervention, the above indexes were decreased to various degrees when compared with the model group. Abnormal proliferation of lung VSMCs is a key factor in PAH (36). Once PAH develops, blood collides with the vascular walls, damaging endothelial cells and leading to their dissociation. Due to the action of numerous cytokines, VSMCs then migrate towards the theca interna and enter mitosis following induction by various types of growth factors present at this site (37). This results in the marked proliferation of VSMCs to form the neointima, which leads to stenosis of the vascular lumen. The proliferating cell nuclear antigen, $\mathrm{Ki67}$, is considered to be an ideal indicator for detecting cell proliferation (38). In the present study, PTX intervention was associated with a significant decrease in expression of $\mathrm{Ki} 67$, and its expression was decreased when compared with the model group. This suggests that $2 \mathrm{mg} / \mathrm{kg}$ PTX may inhibit the proliferation of lung VSMCs in a rat model of PAH. In addition, PTX has been demonstrated to significantly inhibit the migration and proliferation of VSMCs, which has been verified in animal models and clinical trials (39). In addition, Axel et al (32) demonstrated that the local application of PTX in a rabbit model of balloon angioplasty-induced carotid artery restenosis significantly reduced the proliferation of VSMCs in vivo. This was further confirmed by Signore et al (19), whereby the continuous application of PTX in a murine model of carotid artery balloon injury almost completely inhibited intimal hyperplasia. In the present study, a left pneumonectomy was performed with MCT induction to establish a rat model of severe PAH. The results indicated that mPAP was increased significantly, the
RV exhibited hypertrophy, neointimal formation occurred, and stereological indexes, including pulmonary artery thickness, non-muscular musculinization of lung small arteries and neointimal proliferation were increased significantly in the model group when compared with the control group. PTX intervention decreased the above indexes, suggesting that PTX, at a non-cytotoxic concentration, may reduce mPAP in rats and improve PVR in PAH. These preliminary results require further confirmation in future studies that aim to investigate whether the same effects of PTX would be observed in severe cases of PAH that are accompanied by neointimal formation.

Abnormal proliferation of lung VSMCs is the key pathological feature of PAH (40). Similar to other cells, the proliferation of VSMCs involves the cyclical activity of DNA replication and mitosis. The final common pathway of cell proliferation signal transduction is the cell cycle; therefore inhibiting or interrupting the cell cycle is considered to be an effective strategy to inhibit the over-proliferation of VSMCs, and to prevent vascular proliferative diseases (41). The proliferation of VSMCs is regulated by a variety of signal transduction pathways; the most studied of which is the mitogen-activated protein kinase (MAPK) cascade pathway (42). Two key regulatory checkpoints exist in the MAPK cascade pathway at the $\mathrm{G}_{1} / \mathrm{S}$ phase and $\mathrm{G}_{2} / \mathrm{M}$ phases. The $\mathrm{G}_{1} / \mathrm{S}$ regulatory checkpoint involves a reduction in the expression of the cyclin-dependent kinase $(\mathrm{CDK})$ inhibitor, p27 $7^{\mathrm{Kip} 1}(17,43)$, which promotes the proliferation of VSMCs. As a positive regulatory factor of the $G_{2} / M$ phase in the cell cycle, cyclin B1 combines with CDK1, which leads to cell cycle progression from the $G_{1} / S$ 
phase to the $\mathrm{G}_{2} / \mathrm{M}$ phase and promotes karyomitosis (44). High levels of cyclin B1 expression enables cells to progress through the $\mathrm{G}_{2} / \mathrm{M}$ phase checkpoint, which leads to alterations in the structure of important nuclear proteins, progression to $\mathrm{M}$ phase and the subsequent promotion of cell growth and proliferation (14). $\mathrm{p} 27^{\mathrm{Kip} 1}$ protein is a negative regulator of the cell cycle by inhibiting the kinase activity of all cyclin/CDK complexes (45). Through its 69 -amino acid $\mathrm{N}$-terminal region, p2 $7^{\mathrm{kipl}}$ binds cyclin/CDK complexes, thus preventing transformation of CDKs into their active states and inhibiting kinase function (46). It has been reported that $\mathrm{p} 27^{\mathrm{Kipl}}$ serves a key role in regulating the proliferation of pulmonary VSMCs, and the reduced expression of $\mathrm{p} 27^{\mathrm{Kip} 1}$ may be a key factor underlying PVR in PAH (47). Tanner et al (18) identified VSMC proliferation and neointimal formation in the arterial injury phase in a porcine model of arterial injury, and observed low expression levels of $\mathrm{p} 27^{\mathrm{Kipl}}$. By contrast, increased expression of $\mathrm{p} 27^{\mathrm{Kipl}}$ in the vascular intima in the arterial injury phase was associated with inhibited proliferation of VSMCs and reduced neointimal formation. Song et al (48) confirmed this phenomenon in a neointimal experiment involving VSMCs. Over expression of $\mathrm{p} 27^{\mathrm{Kipl}}$ protein inhibited the cell cycle in $\mathrm{G}_{1}$ phase, and reduced VSMC proliferation and neointimal formation (49). Down regulation of $\mathrm{p} 27^{\mathrm{Kipl}}$ has been demonstrated to increase neointimal formation and cell aggregation following inflammatory mechanical vascular injury $(40,50,51)$, indicating that VSMC proliferation is associated with the expression levels of p2 $7^{\text {Kipl }}$, which may therefore serve a key function in the repair and remodeling process following arterial injury. Thus, $\mathrm{p} 27^{\mathrm{Kipl}}$ may present a potential therapeutic target for the treatment of vascular proliferative diseases.

During progression through the $\mathrm{G}_{2} / \mathrm{M}$ phase, cyclin $\mathrm{B} 1 / \mathrm{CDK} 1$ serves a key role in promoting cells to convert from DNA synthesis to mitosis (52-54). Granada et al (55) cultured rat aortic smooth muscle cells in vitro, and demonstrated that a high concentration of mitomycin C (MMC) inhibited the proliferation of smooth muscle cells at the $\mathrm{G}_{2} / \mathrm{M}$ phase, thus leading to apoptosis of VSMCs. Low concentrations of MMC inhibited the proliferation of VSMCs, which was demonstrated to be associated with the reduced activity of cyclin B1/CDK1. In addition, MMC significantly inhibited neointimal formation in a rat model of carotid artery balloon-induced injury (56). The current study demonstrated that PTX inhibited the proliferation of lung VSMCs in a rat model of PAH. The results of immunohistochemistry and western blot analyses indicated that the expression of $\mathrm{p} 27^{\mathrm{Kip} 1}$ was significantly higher in the PTX group when compared with the model group, while the expression of cyclin B1 was significantly lower compared with the model group. Therefore, the results of the present study suggest that the expression of $\mathrm{p} 27^{\mathrm{Kipl}}$ and cyclin $\mathrm{B} 1$ in rats from each experimental group were negatively correlated. This may be due to the persistent expression of $\mathrm{p} 27^{\mathrm{Kipl}}$ throughout the cell cycle. Upon stimulation of VSMCs by the proliferation signal, $\mathrm{p} 27^{\mathrm{Kip} 1}$ is rapidly degraded by protein ubiquitination (57), which leads to increased expression of cyclin B1, thus promoting progression through the $\mathrm{G}_{2} / \mathrm{M}$ phase and accelerating cell proliferation. These alterations in $\mathrm{p} 27^{\mathrm{Kipl}}$ and cyclin B1 expression were observed in the model group when compared with the control group. Following intervention with PTX, the expression of these factors was significantly reversed, resulting in reduced cyclin B1 expression and inhibiting the proliferation of VSMCs. Based on these observations, the authors of the present study hypothesize that the mechanism by which PTX inhibits the proliferation of lung VSMCs in a rat model of PAH, may involve the increased expression of p27 $7^{\mathrm{Kipl}}$ and the decreased expression of cyclin B1.

The proliferation and migration of VSMCs is associated with a number of signal transduction pathways, including the MAPK, Ras-phosphoinositide 3-kinase-Akt, Janus kinase/signal transducers and activators of transcription and the nuclear factor- $\mathrm{\kappa B}$ signaling pathways (58). A wide-range of complex mechanisms exist among these pathways, these signaling pathways have a number of common factors that link the networks together to form a complex signaling network (59). The current study demonstrated that treatment with PTX at a non-cytotoxic concentration may inhibit the proliferation of lung VSMCs, thus improving PVR in a rat model of PAH. In addition, the results suggest that this effect may be associated with the increased expression of the cell cycle inhibitory factor, $\mathrm{p} 27^{\mathrm{Kip} 1}$ and the decreased expression of cyclin B1. However, in order to identify the signal transduction pathways and possible mechanisms by which PTX inhibits the proliferation of VSMCs, further studies will be required.

The proliferation of VSMCs has been considered to be the most important characteristic of vascular proliferative disease (60). Molecular studies investigating vascular proliferative disease have revealed that its mechanisms are very complex, and involve a large number of cytokines and physiochemical factors (61). Therefore, it would be ineffective and impossible to target and reverse each risk factor; however, these factors ultimately lead to chronic vascular remodeling. Identifying a strategy to inhibit the proliferation of VSMCs at the cellular level is therefore critical. At nanoscale concentrations, PTX exhibited inhibitory effects on the proliferation of VSMCs in the current study. The results of previous studies suggest that PTX may be used to treat PAH; however the solubility of commercial PTX formulations leads to an increased number of side effects (62). Therefore, a safe and effective drug-transport system is required, whereby the efficacy of PTX is increased, and the ability of PTX to enter cells is enhanced, thus improving anti-proliferative effects while ensuring the safest conditions. The selection of an appropriate drug concentration and the development of novel PTX formulations may achieve these aims when applying PTX for the treatment of vascular proliferative diseases such as $\mathrm{PAH}$, while reducing its toxicity.

There were some notable limitations of the current study. Firstly, only a single dose of PTX was used, and the effects of different PTX doses within a low-concentration range were not investigated in the rat model of PAH. Secondly, this study did not assess the preventative effect of PTX on PAH. Thirdly, this study performed a preliminary investigation of the mechanisms underlying the inhibitory effects of PTX on VSMCs. Therefore, the precise signal transduction pathways and mechanisms involved will require further investigation in future studies.

\section{Acknowledgements}

Not applicable. 


\section{Funding}

The present study was supported by the National Natural Science Foundation of China (grant no. 81370220) and the Specialized Doctoral Research Foundation of the Ministry of Education of China (grant no. 20130181110056).

\section{Availability of data and materials}

All data generated or analyzed during the present study are included in this published article.

\section{Authors' contributions}

$\mathrm{JZ}$ and BL contributed to the conception and design of the study. JZ, MY, ZY, PJ, YS, GL, LX and HL designed and performed the experiments. JZ, MY, XW and ZY acquired, analyzed and interpreted the data. JZ and BL drafted and revised the manuscript. All authors read and approved the final version of the manuscript.

\section{Ethics approval and consent to participate}

The present study was performed in accordance with the recommendations in the Guide for the Care and Use of Laboratory Animals of the National Institutes of Health. The animal use protocol was reviewed and approved by Experiment Animal Administrative Committee of Sichuan University (Chengdu, China).

\section{Patient consent for publication}

Not applicable.

\section{Competing interests}

The authors declare that they have no competing interests.

\section{References}

1. Satoh T: Current practice for pulmonary hypertension. Chin Med J (Engl) 127: 3491-3195, 2014.

2. Stein PD, Matta F and Hughes PG: Scope of problem of pulmonary arterial hypertension. Am J Med 128: 844-851, 2015.

3. Ball MK, Waypa GB, Mungai PT, Nielsen JM, Czech L, Dudley VJ, Beussink L, Dettman RW, Berkelhamer SK, Steinhorn RH, et al: Regulation of hypoxia-induced pulmonary hypertension by vascular smooth muscle hypoxia-inducible factor-1 $\alpha$. Am J Respir Crit Care Med 189: 314-324, 2014.

4. Pullamsetti SS, Schermuly R, Ghofrani A, Weissmann N, Grimminger F and Seeger W: Novel and emerging therapies for pulmonary hypertension. Am J Respir Crit Care Med 189: 394-400, 2014.

5. Jeffery TK and Wanstall JC: Pulmonary vascular remodeling: A target for therapeutic intervention in pulmonary hypertension. Pharmacol Ther 92: 1-20, 2001.

6. Kim DW, Kwon JS, Kim YG, Kim MS, Lee GS, Youn TJ and Cho MC: Novel oral formulation of paclitaxel inhibits neointimal hyperplasia in a rat carotid artery injury model. Circulation 109: 1558-1563, 2004.

7. Wöhrle J, Birkemeyer R, Markovic S, Nguyen TV, Sinha A, Miljak T, Spiess J, Rottbauer W and Rittger H: Prospective randomised trial evaluating a paclitaxel-coated balloon in patients treated with endothelial progenitor cell capturing stents for de novo coronary artery disease. Heart 97: 1338-1342, 2011.

8. Zhang Z, Mei L and Feng SS: Paclitaxel drug delivery systems. Expert Opin Drug Deliv 10: 325-340, 2013.
9. Seedial SM, Ghosh S, Saunders RS, Suwanabol PA, Shi X, Liu B and Kent KC: Local drug delivery to prevent restenosis. J Vasc Surg 57: 1403-1414, 2013.

10. Waugh $\mathrm{J}$ and Wagstaff AJ: The paclitaxel (TAXUS)-eluting stent: A review of its use in the management of de novo coronary artery lesions. Am J Cardiovasc Drugs 4: 257-268, 2004.

11. Leopardi M, Houbballah R and Becquemin JP: Effectiveness of Zilver PTX eluting stent in TASC C/D lesions and restenosis. J Cardiovasc Surg (Torino) 55: 229-234, 2014.

12. Yang J, Zeng Y, Zhang C, Chen YX, Yang Z, Li Y, Leng X, Kong D, Wei XQ, Sun HF and Song CX: The prevention of restenosis in vivo with a VEGF gene and paclitaxel co-eluting stent. Biomaterials 34: 1635-1643, 2013.

13. Schiff PB, Fant J and Horwitz SB: Promotion of microtubule assembly in vitro by taxol. Nature 277: 665-667, 1979.

14. Lohberger B, Leithner A, Stuendl N, Kaltenegger H, Kullich W and Steinecker-Frohnwieser B: Diacerein retards cell growth of chondrosarcoma cells at the $\mathrm{G} 2 / \mathrm{M}$ cell cycle checkpoint via cyclin B1/CDK1 and CDK2 downregulation. BMC Cancer 15: 891, 2015.

15. Chen X, Gu Y, Singh K, Shang C, Barzegar M, Jiang S and Huang S: Maduramicin inhibits proliferation and induces apoptosis in myoblast cells. PLoS One 9: e115652, 2014.

16. Tsui LV, Camrud A, Mondesire J, Carlson P, Zayek N, Camrud L, Donahue B, Bauer S, Lin A, Frey D, et al: p27-p16 fusion gene inhibits angioplasty-induced neointimal hyperplasia and coronary artery occlusionn. Circ Res 89: 323-328, 2001.

17. Li XW, Hu CP, Wu WH, Zhang WF, Zou XZ and Li YJ: Inhibitory effect of calcitonin gene-related peptide on hypoxia-induced rat pulmonary artery smooth muscle cells proliferation: Role of ERK1/2 and p27. Eur J Pharmacol 679: 117-126, 2012.

18. Tanner FC, Yang ZY, Duckers E, Gordon D, Nabel GJ and Nabel EG: Expression of cyclin-dependent kinase inhibitors in vascular disease. Circ Res 82: 396-403, 1998.

19. Signore PE, Machan LS, Jackson JK, Burt H, Bromley P, Wilson JE and McManus BM: Complete inhibition of intimal hyperplasia by perivascular delivery of paclitaxel in balloon-injured rat carotid arteries. J Vasc Interv Radiol 12: 79-88, 2001.

20. Kusuma SS, Tanneeru K, Didla S, Devendra BN and Kiranmayi P: Antineoplastic activity of monocrotaline against hepatocellular carcinoma. Anticancer Agents Med Chem 14: 1237-1248, 2014.

21. Schermuly RT, Kreisselmeier KP, Ghofrani HA, Yilmaz H, Butrous G, Ermert L, Ermert M, Weissmann N, Rose F, Guenther A, et al: Chronic sildenafil treatment inhibits monocrotaline-induced pulmonary hypertension in rats. Am J Respir Crit Care Med 169: 39-45, 2004.

22. Liu B, Liu HM, Yu L, Sun XJ, Wei L, Wang XM and Zhou TF: Expression of GATA6 gene in lung tissue of rat with pulmonary hypertension. Sichuan Da Xue Xue Bao Yi Xue Ban 37: 864-867, 875, 2006 (In Chinese).

23. Dettmer S, Peters L, de Wall C, Schaefer-Prokop C, Schmidt M, Warnecke G, Gottlieb J, Wacker F and Shin HO: Bronchial wall measurements in patients after lung transplantation: Evaluation of the diagnostic value for the diagnosis of bronchiolitis obliterans syndrome. PLoS One 9: e93783, 2014.

24. Hoshikawa Y, Ono S, Suzuki S, Tanita T, Chida M, Song C, Noda M, Tabata T, Voelkel NF and Fujimura S: Generation of oxidative stress contributes to the development of pulmonary hypertension induced by hypoxia. J Appl Physiol (1985) 90: 1299-1306, 2001.

25. Runo JR and Loyd JE: Primary pulmonary hypertension. Lancet 361: 1533-1544, 2003.

26. Li J, Wang Y,Zhu Y and Oupický D: Recent advances in delivery of drug-nucleic acid combinations for cancer treatment: J Control Release 172: 589-600, 2013.

27. Zhang D, Yang R, Wang S and Dong Z: Paclitaxel: New uses for an old drug. Drug Des Devel Ther 8: 279-284, 2014.

28. Kumar A, Hoskins PJ and Tinker AV: Dose-dense paclitaxel in advanced ovarian cancer. Clin Oncol (R Coll Radiol) 27: 40-47, 2015.

29. Howat S, Park B, Oh IS, Jin YW, Lee EK and Loake GJ: Paclitaxel: biosynthesis, production and future prospects. $\mathrm{N}$ Biotechnol 31: 242-245, 2014.

30. Choi BM, Kim YM, Jeong YR, Pae HO, Song CE, Park JE, Ahn YK and Chung HT: Induction of heme oxygenase-1 is involved in anti-proliferative effects of paclitaxel on rat vascular smooth muscle cells. Biochem Biophys Res Commun 321: 132-137, 2004. 
31. Hemmer JD, Nagatomi J, Wood ST, Vertegel AA, Dean D and Laberge M: Role of cytoskeletal components in stress-relaxation behavior of adherent vascular smooth muscle cells. J Biomech Eng 131: 041001, 2009.

32. Axel DI, Kunert W, Göggelmann C, Oberhoff M, Herdeg C, Küttner A, Wild DH, Brehm BR, Riessen R, Köveker G and Karsch KR: Paclitaxel inhibits arterial smooth muscle cell proliferation and migration in vitro and in vivo using local drug delivery. Circulation 96: 636-645, 1997.

33. Wiskirchen J, Schöber W, Schart N, Kehlbach R, Wersebe A Tepe G, Claussen CD and Duda SH: The effects of paclitaxel on the three phases of restenosis: Smooth muscle cell proliferation, migration, and matrix formation: An in vitro study. Invest Radiol 39: 565-571, 2004

34. Tian W, Kuhlmann MT, Pelisek J, Scobioala S, Quang TH, Hasib L, Klocke R, Jahn UR and Nikol S: Paclitaxel delivered to adventitia attenuates neointima formation without compromising re-endothelialization after angioplasty in a porcine restenosis model. J Endovasc Ther 13: 616-629, 2006.

35. Schwartz EL: Antivascular actions of microtubule-binding drugs. Clin Cancer Res 15: 2594-2601, 2009.

36. Shimoda LA and Laurie SS: Vascular remodeling in pulmonary hypertension. J Mol Med (Berl) 91: 297-309, 2013.

37. Foris V, Kovacs G, Tscherner M,Olschewski A and Olschewski H: Biomarkers in pulmonary hypertension: What do we know? Chest 144: 274-283, 2013.

38. Lluis M, Fernández-Solà J, Castellvi-Bel S, Sacanella E, Estruch R and Urbano-Márquez A: Evaluation of myocyte proliferation in alcoholic cardiomyopathy: Telomerase enzyme activity (TERT) compared with Ki-67 expression. Alcohol Alcohol 46: 534-541, 2011

39. Jing L, Peng X, Xie MJ, Yu ZY and Wang W: Different responses of cell cycle between rat vascular smooth muscle cells and vascular endothelial cells to paclitaxel. J Huazhong Univ Sci Technolog Med Sci 34: 370-375, 2014.

40. Wu X, Huang L, Zhou Q, Song Y, Li A, Wang H and Song M: Effect of paclitaxel and mesenchymal stem cells seeding on ex vivo vascular endothelial repair and smooth muscle cells growth. J Cardiovasc Pharmacol 46: 779-786, 2005.

41. Marx SO, Totary-Jain H and Marks AR: Vascular smooth muscle cell proliferation in restenosis. Circ Cardiovasc Interv 4: 104-111, 2011.

42. Lao LL and Venkatraman SS: Adjustable paclitaxel release kinetics and its efficacy to inhibit smooth muscle cells proliferation. J Control Release 130: 9-14, 2008

43. Yoon MK, Mitrea DM, Ou L and Kriwacki RW: Cell cycle regulation by the intrinsically disordered proteins $\mathrm{p} 21$ and $\mathrm{p} 27$. Biochem Soc Trans 40: 981-988, 2012.

44. Wang Z, Fan M, Candas D, Zhang TQ, Qin L, Eldridge A, Wachsmann-Hogiu S, Ahmed KM, Chromy BA, Nantajit D, et al: Cyclin B1/Cdk1 coordinates mitochondrial respiration for cell-cycle G2/M progression. Dev Cell 29: 217-232, 2014.

45. Sharma SS, Ma L and Pledger WJ: p27Kip1 inhibits the cell cycle through non-canonical G1/S phase-specific gatekeeper mechanism. Cell Cycle 14: 3954-3964, 2015

46. Bryant P, Zheng Q and Pumiglia K: Focal adhesion kinase controls cellular levels of p27/Kip1 and p21/Cip1 through Skp2-dependent and -independent mechanisms. Mol Cell Biol 26: 4201-4213, 2006

47. Fouty BW, Grimison B, Fagan KA, Le Cras TD, Harral JW, Hoedt-Miller M, Sclafani RA and Rodman DM: p27(Kip1) is important in modulating pulmonary artery smooth muscle cell proliferation. Am J Respir Cell Mol Biol 25: 652-658, 2001.
48. Song P, Wang S, He C, Wang S, Liang B, Viollet B and Zou MH: AMPK $\alpha 2$ deletion exacerbates neointima formation by upregulating Skp2 in vascular smooth muscle cells. Circ Res 109: $1230-1239,2011$

49. Roy A and Banerjee S: p27 and leukemia: Cell cycle and beyond. J Cell Physiol 230: 504-509, 2015.

50. Tanner FC, Boehm M, Akyürek LM, San H, Yang ZY, Tashiro J, Nabel GJ and Nabel EG: Differential effects of the cyclin-dependent kinase inhibitors p27(Kip1), p21(Cip1), and p16(Ink4) on vascular smooth muscle cell proliferation. Circulation 101: 2022-2025, 2000.

51. Chang MW, Barr E, Lu MM, Barton K and Leiden JM: Adenovirus-mediated over-expression of the cyclin/cyclin-dependent kinase inhibitor, p21 inhibits vascular smooth muscle cell proliferation and neointima formation in the rat carotid artery model of balloon angioplasty. J Clin Invest 96: 2260-2268, 1995.

52. Murray AW: Recycling the cell cycle: Cyclins revisited. Cell 116: 221-234, 2004.

53. Lenart P, Rabut G, Daigle N, Hand AR, Terasaki M and Ellenberg J: Nuclear envelope breakdown in starfish oocytes proceeds by partial NPC disassembly followed by a rapidly spreading fenestration of nuclear membranes. J Cell Biol 160: $1055-1068,2003$

54. Terasaki M, Okumura E, Hinkle B and Kishimoto T: Localization and dynamics of $\mathrm{Cdc} 2$-cyclin $\mathrm{B}$ during meiotic reinitiation in starfish oocytes. Mol Biol Cell 14: 4685-4694, 2016.

55. Granada JF, Ensenat D, Keswani AN, Kaluza GL, Raizner AE, Liu XM, Peyton KJ, Azam MA, Wang H and Durante W: Single perivascular delivery of mitomycin $C$ stimulates p21 expression and inhibits neointima formation in rat arteries. Arterioscler Thromb Vasc Biol 25: 2343-2348, 2005.

56. Tang L, Chen X, Tang S, LaLonde T and Gardin JM: Granulation encapsulated stent: A new therapeutic approach for vascular implantation. Heart 93: 238-243, 2006.

57. Sugihara E, Kanai M,Saito S, Nitta T, Toyoshima H, Nakayama K, Nakayama KI, Fukasawa K, Schwab M, Saya H and Miwa M: Suppression of centrosome amplification after DNA damage depends on p27 accumulation. Cancer Res 66: 4020-4029, 2006.

58. Zhang X, Liu J, Pang X, Zhao J, Wang S and Wu D: Aldosterone induces $C$-reactive protein expression via MR-ROS-MAPK-NF- $\mathrm{BB}$ signal pathway in rat vascular smooth muscle cells. Mol Cell Endocrinol 395: 61-68, 2014.

59. Ouyang QF, Han Y,Lin ZH, Xie H, Xu CS and Xie LD: Fluvastatin upregulates the $\alpha 1 \mathrm{C}$ subunit of $\mathrm{CaV} 1.2$ channel expression in vascular smooth muscle cells via RhoA and ERK/p38 MAPK pathways. Dis Markers 2014: 237067, 2014.

60. Proudfoot D and Shanahan C: Human vascular smooth muscle cell culture. Methods Mol Biol 806: 251-263, 2012.

61. Andrés V and Castro C: Antiproliferative strategies for the treatment of vascular proliferative disease. Curr Vasc Pharmacol 1: 85-98, 2003.

62. Yin Y, Wu X, Yang Z, Zhao J, Wang X, Zhang Q, Yuan M, Xie L, Liu H and He Q: The potential efficacy of R8-modified paclitaxel-loaded liposomes on pulmonary arterial hypertension. Pharm Res 30: 2050-2062, 2013

This work is licensed under a Creative Commons Attribution-NonCommercial-NoDerivatives 4.0 International (CC BY-NC-ND 4.0) License. 